REVIEW ARTICLE

\title{
Late-onset Fetal Growth Restriction: Or Just Ultrasound?
}

\author{
Sebastian Kwiatkowski
}

\begin{abstract}
Late-onset fetal growth restriction (FGR) is still a diagnostic challenge. Current criteria are based on ultrasonography in which biometric measurements and Doppler flows are used. Differentiation between the constitutional low birth weight and FGR is still being explored. Diagnostic methods that clearly indicate a group of fetuses with FGR may prove to be key in developing algorithms.

Keywords: Biochemical markers, Biophysical markers, Epigenetic, Fetal growth restriction, Ultrasound.

Donald School Journal of Ultrasound in Obstetrics and Gynecology (2020): 10.5005/jp-journals-10009-1645
\end{abstract}

Fetal growth disorders are one of the more common causes of obstetric pathologies. According to various sources, they develop in nearly $10 \%$ of pregnancies. ${ }^{1}$ Low neonatal birth weight is a risk factor for both perinatal morbidity and mortality. ${ }^{2}$ As long-term observation shows, it is also a risk factor for many metabolic diseases, cardiovascular diseases, ${ }^{3}$ and mental ${ }^{4}$ and renal dysfunction. $^{5}$

Growth disorders can have varying etiologies, starting from genetic causes, as some chromosome aberrations or monogenetic disorders coexist with severe syndromes, to anatomical malformations that predispose the fetus to growth restriction. Congenital infections are another possible cause. ${ }^{6}$ Placental causes of varying etiologies are, however, among the most common. ${ }^{7}$ During pregnancy, two types of growth disorders are observed: those that develop very early and are referred to as early-onset and those that develop in the final stage of pregnancy and are referred to as late-onset growth restriction. ${ }^{8}$ Observations indicate that this division has profound pathogenic grounds.

The placenta is designed to function over a limited period of time. During the first half of the pregnancy, the uteroplacental compartment providing adequate fetal-maternal exchange is formed. Disturbances in this process are most likely to lead to the development of early-onset syndromes, although moderate placental disorders may also affect late-onset growth disorders. ${ }^{9}$ However, as observations show, placental dysfunction caused by accelerated impairment of its metabolism and structural degeneration plays a decisive role in the development of the late-onset growth restriction. ${ }^{10,11}$ This process is generally referred to as aging of the placenta, but the etiology varies and usually includes comorbidities such as hypertension, diabetes mellitus and metabolic syndrome, or the drugs being taken, the use of tobacco, alcohol or drugs, and patient age. In addition, local elements, such as the location of the placenta, OB history, structure of the place of the placenta, cord insertion, and cord structure, may have an impact. ${ }^{12}$ Usually, the circumstances leading to the development of the condition are complex. Some statistical models allow a hypothetical assumption that an extending gestation beyond the 50th week would result in the development of placental insufficiency in almost all women. ${ }^{13}$

The current methods for diagnosing aging in the placenta and its relationship with intrauterine growth restriction are either very limited or undergoing research evaluation. Ultrasound remains the most common method used in diagnosing and monitoring growth restriction. The diagnostic model worked out in 2016 by way of the
Department of Obstetrics and Gynecology, Pomeranian Medical University in Szczecin, Poland

Corresponding Author: Sebastian Kwiatkowski, Department of Obstetrics and Gynecology, Pomeranian Medical University in Szczecin, Poland, Phone: +48 570888 100, e-mail: kwiatkowskiseba@gmail.com

How to cite this article: Kwiatkowski S. Late-onset Fetal Growth Restriction: Or Just Ultrasound? Donald School J Ultrasound Obstet Gynecol 2020;14(3):195-197.

Source of support: Nil

Conflict of interest: None

Delphi method has become a benchmark for many countries. ${ }^{14}$ This development is of particular significance, as prior to that everyone did that their own way. It is difficult to reach an agreement between research centers and different countries if the cutoff point is set at the 3rd percentile by some and at the 5th or 10th by others. The Doppler ultrasound criteria have further clarified the diagnoses. However, estimated fetal weight and, after delivery, neonatal birth weight remain the main assessment criteria. The question remains whether these parameters are sufficient or not, especially since a significant proportion of low-weight cases are constitutional and do not subsequently demonstrate metabolic disorders or distant health consequences. ${ }^{15}$

The late-onset intrauterine growth restriction diagnosis is made upon a biometric assessment and obtaining an estimated fetal weight or abdominal circumference (AC) below the 10th percentile for gestational age together with concomitant Doppler flow disturbances. Where the estimated fetal weight or AC fall below the third percentile, this criterion is sufficient. The vessels most commonly used to evaluate the flows are umbilical arteries and middle cerebral arteries. Additional parameters used are the cerebroplacental ratio derived from the pulsatility index for both the vessels, and the so-called growth trajectory, in the case of which it is important to detect a leap on the growth chart observed over a time interval. A two-quartile leap is considered significant. ${ }^{14}$

Evaluation using the growth charts and the diagnostic parameters remains a separate issue. We are talking about standardized growth charts for the given populations as well as personalized growth charts. ${ }^{16}$ Scientists are currently in dispute over which of them have a higher diagnostic value and, above all, which correlate with the perinatal outcomes more accurately. The supporters of personalized growth charts claim they are much 
more precise at predicting neonates ${ }^{17}$ will demonstrate a poorer birth status and require intervention such as, for instance, intensive care. ${ }^{18}$ The opponents suggest, however, that personalized growth charts increase early intervention rates, leading to a higher preterm labor prevalence and, consequently, more frequent neonatal complications. ${ }^{19}$ Presently, most societies suggest the use of population charts, including those developed by Hadlock. ${ }^{20}$

As experience and the existing diagnostic models used in perinatal medicine show, the most favorable and effective results are achieved when the biophysical parameters are combined with the biochemical ones. We have used this regimen in first trimester chromosome aberration screening for a long time, and similar models have been developed for detecting high-risk preeclampsia groups $^{21}$ and groups with a risk of preterm labor. ${ }^{22}$ It appears that one of the directions for seeking more precise methods is to combine different methods also in the search for tools for the prediction and, above all, the diagnosis of late-onset FGR. The existing predictive models make use of biometric assessments to forecast late-onset FGR and include a review of medical history for risk factors, blood pressure measurements, and uterine artery Doppler ultrasound measurements. These algorithms, even when used at approximately 30 weeks' gestation, do not allow for detecting the group of patients who will develop FGR after 37 weeks' gestation. They are only effective in predictions for the coming to weeks. ${ }^{23-25}$ Because of this, increasing attention is being paid to the concept that the higher-risk groups should have an ultrasound performed more frequently toward the end of pregnancy. Two models are being promoted which suggest that scans be performed every 3 weeks starting from 28 weeks' gestation ${ }^{26}$ or-where the results are normal-a scan be performed at approximately 30 weeks' gestation and another one at approximately $35-37$ weeks' gestation. ${ }^{27}$ Both these models are currently in the evaluation phase. However, the diagnosis of estimated fetal weight below the 10th percentile still does not legitimize a growth restriction diagnosis, as according to the available data approximately $65-70 \%$ of such cases are constitutional, with the rate falling when the cut-off point is set at the 5th percentile. Setting the cut-off point at the 3rd percentile reverses that rate, meaning that approximately $70 \%$ of fetuses demonstrate FGR. ${ }^{28}$

The search for tools to differentiate between small for gestational age (SGA) and FGR has taken two separate routes. Some scientists are attempting to use increasingly sophisticated ultrasound tools. There are reports pointing to differences in cardiac function assessments, for example in the MPI (the Tei index) between FGR and AGA fetuses. ${ }^{29}$ Changes in the aortic isthmus flows have been observed for a quite long time. ${ }^{30} \mathrm{New}$ indicators are also being developed, such as the one proposed by Rizze (UVBF/ AC) assessing the differences in the umbilical vein flow. ${ }^{31}$ However, these are still proposals that require extensive clinical and hardware experience.

The second solution that, using the modern diagnostic methods, may become a breakthrough in assessing the birth status and predicting distant complications of FGR is evaluation of the placenta. The Amsterdam criteria for placentology have introduced standards for histopathological evaluation. ${ }^{32} \mathrm{~A}$ specific regime allows an organized and precise picture of placental function disorders and, above all, their scale to be obtained. We are presently arriving at a preliminary explanation of the possible causes of the organ's premature failure. Certainly, the fact that a histopathological examination can only be performed after labor is a limitation, as a midgestational assessment of the aforementioned pathologies is impossible. If this diagnostic area develops to include the possibility of identifying the lesions that are specific to FGR and, for instance, absent in SGA fetuses, it could turn out to be an excellent tool for predicting the risk of both near and distant complications in children. The use of modern molecular and immunohistochemical methods in evaluation of the placenta, as well as other areas of histopathology, can certainly be a breakthrough. The use of monoclonal antibodies as markers of impaired villi development has shown that the diagnosis of these pathologies is becoming much more precise ${ }^{11}$. Aging of the placenta is another focus of research making use of parameters assessing apoptosis markers, such as CASP, and markers such as telomerase activity or telomere shortening. ${ }^{10}$ Another very promising aspect that undoubtedly affects placental function is the epigenetic processes that occur in both fetuses exposed to placental dysfunction and in the organ itself. ${ }^{33}$

Based on the experience gained to date, it can be noted that the optimal situation would be to have additional parameters at our disposal that are available during pregnancy which would complement the ultrasound examination. ${ }^{34}$ At present, it is difficult to indicate clearly which group of agents will meet these expectations. PIGF, which is currently used for screening and diagnosis of preeclampsia, correlates with lower neonatal birth weight. ${ }^{35,36}$ However, it still does not allow for differentiating between FGR and SGA fetuses. Similarly, other biochemical markers such as hCG, AFP, and PAPPA allow a small degree of prediction of low neonatal birth weight but fail at differentiating pathologies from constitutional weights. ${ }^{37,38}$ Fetal DNA ${ }^{39}$ and microRNA molecules are also under investigation. ${ }^{40}$ As mentioned earlier, where there is limited availability of nutrients or in cases of growth restriction, fetal metabolism changes and adapts by switching into the so-called "saving mode." This is one example of fetal programming, which plays a role not only in the postpartum period but also in later life. ${ }^{41}$ Changes in the expression of individual genes are most frequently modified through epigenetic mechanisms. The processes of DNA methylation, histone modification, and microRNA attachment may determine the final phenotype formed as a result of unfavorable midgestational intrauterine conditions. ${ }^{42,43}$ It appears highly likely that if markers are discovered that offer unequivocal results in predicting fetal development, they may also allow for unambiguous differentiation between FGR fetuses and fetuses with constitutional low weight (SGA).

\section{References}

1. Damodaram M, Story L, Kulinskaya E, et al. Early adverse perinatal complications in preterm growth-restricted fetuses. Aust New Zeal J Obstet Gynaecol 2011;51(3):204-209. DOI: 10.1111/j.1479828X.2011.01299.x.

2. Jarvis S, Glinianaia SV, Torrioli MG, et al. Cerebral palsy and intrauterine growth in single births: European collaborative study. Lancet 2003;362(9390):1106-1111. DOI: 10.1016/S0140-6736(03)14466-2.

3. McMillen IC, Robinson JS. Developmental origins of the metabolic syndrome: Prediction, plasticity, and programming. Physiol Rev 2005;85(2):571-633. DOI: 10.1152/physrev.00053.2003.

4. Miller SL, Huppi PS, Mallard C. The consequences of fetal growth restriction on brain structure and neurodevelopmental outcome. J Physiol 2016;594(4):807-823. DOI: 10.1113/JP271402.

5. Bacchetta J, Harambat J, Dubourg L, et al. Both extrauterine and intrauterine growth restriction impair renal function in children born very preterm. Kidney Int 2009;76(4):445-452. DOI: 10.1038/ ki.2009.201. 
6. Sharma D, Shastri S, Farahbakhsh N, et al. Intrauterine growth restriction-part 1. J Matern Neonatal Med 2016;29(24):3977-3987. DOI: 10.3109/14767058.2016.1152249.

7. Burton GJ, Jauniaux E. Pathophysiology of placental-derived fetal growth restriction. Am J Obstet Gynecol [Internet] 2018;218(2): S745-S761. DOI: 10.1016/j.ajog.2017.11.577.

8. Figueras F, Gratacos E. Stage-based approach to the management of fetal growth restriction. Prenat Diagn 2014;34(7):655-659. DOI: 10.1002/pd.4412.

9. Spinillo A, Gardella B, Adamo L, et al. Pathologic placental lesions in early and late fetal growth restriction. Acta Obstet Gynecol Scand 2019;98(12):1585-1594. DOI: 10.1111/aogs.13699.

10. Paules C, Dantas AP, Miranda J, et al. Premature placental aging in term small-for-gestational-age and growth-restricted fetuses. Ultrasound Obstet Gynecol 2019;53(5):615-622. DOI: 10.1002/uog.20103.

11. Jaiman $S$, Romero R, Pacora $P$, et al. Disorders of placental villous maturation in fetal death. J Perinat Med 2020;48(4):345-368. DOI: 10.1515/jpm-2020-0030.

12. Ismail KI, Hannigan A, O'Donoghue K, et al. Abnormal placental cord insertion and adverse pregnancy outcomes: a systematic review and meta-analysis. Syst Rev 2017;6(1):1-11. DOI: 10.1186/s13643-017-0641-1.

13. Poon LC, Nicolaides KH, 297397. 2014; 2014 (Table 2).

14. Gordijn SJ, Beune IM, Wynia K. Consensus definition of fetal growth restriction: a delphi procedure. Ultrasound Obstet Gynecol 2016;48(3):333-339. DOI: 10.1002/uog.15884.

15. Ganzevoort W, Thilaganathan B, Baschat A, et al. Fetal growth and risk assessment: is there an impasse? Point. Am J Obstet Gynecol 2019;220(1):74-82. DOI: 10.1016/j.ajog.2018.10.007.

16. Gardosi J, Francis A, Turner S, et al. Customized growth charts: rationale, validation and clinical benefits. Am J Obstet Gynecol [Internet] 2018;218(2):S609-S618. DOI: 10.1016/j.ajog.2017.12.011.

17. Odibo AO, Francis A, Cahill AG, et al. Association between pregnancy complications and small-for-gestational-age birth weight defined by customized fetal growth standard versus a populationbased standard. J Matern Neonatal Med 2011;24(3):411-417. DOI: 10.3109/14767058.2010.506566.

18. Agarwal P, Rajadurai VS, Yap F, et al. Comparison of customized and cohort-based birthweight standards in identification of growthrestricted infants in GUSTO cohort study. J Matern Neonatal Med 2016;29(15):2519-2522.

19. Zhang $X$, Platt RW, Cnattingius $S$, et al. The use of customised versus population-based birthweight standards in predicting perinatal mortality. BJOG An Int J Obstet Gynaecol 2007;114(4):474-477. DOI: 10.1111/j.1471-0528.2007.01273.x.

20. Martins JG, Biggio JR, Abuhamad A. Society for maternal-fetal medicine (SMFM) consult series \#52: diagnosis and management of fetal growth restriction. Am J Obstet Gynecol [Internet] 2020. DOI: 10.1016/j.ajog.2020.05.010.

21. Rolnik DL, Wright D, Poon LC, et al. Aspirin versus placebo in pregnancies at high risk for preterm preeclampsia. N Engl J Med 2017;377(7):613-622. DOI: 10.1056/NEJMoa1704559.

22. Di Renzo GC, Cabero Roura L, Facchinetti F, et al. Preterm labor and birth management: recommendations from the Ruropean association of perinatal medicine. J Matern Neonatal Med 2017;30(17):2011-2030. DOI: 10.1080/14767058.2017.1323860.

23. Bakalis S, Gallo DM, Mendez O, et al. Prediction of small-forgestational-age neonates: screening by maternal biochemical markers at 30-34 weeks. Ultrasound Obstet Gynecol 2015;46(2): 208-215. DOI: 10.1002/uog.14861.

24. Miranda J, Rodriguez-Lopez M, Triunfo S, et al. Prediction of fetal growth restriction using estimated fetal weight vs a combined screening model in the third trimester. Ultrasound Obstet Gynecol 2017;50(5):603-611. DOI: 10.1002/uog.17393.

25. Birdir C, Droste L, Fox L, et al. Predictive value of sFlt-1, PIGF, sFlt-1/ PIGF ratio and PAPP-A for late-onset preeclampsia and IUGR between 32 and 37 weeks of pregnancy. Pregnancy Hypertens [Internet] 2018;12(February):124-128. DOI: 10.1016/j.preghy.2018.04.010.
26. Williams M, Turner S, Butler E, et al., Fetal growth surveillance Current guidelines, practices and challenges. 2018.

27. Ciobanu A, Rouvali A, Syngelaki A, et al. Prediction of small for gestational age neonates: screening by maternal factors, fetal biometry, and biomarkers at 35-37 weeks' gestation. Am J Obstet Gynecol [Internet] 2019;220(5):486.e1-486.e11. DOI: 10.1016/ j.ajog.2019.01.227.

28. Wright D, Wright A, Smith E, et al. Impact of biometric measurement error on identification of small- and large-for-gestational-age fetuses. Ultrasound Obstet Gynecol 2020;55(2):170-176. DOI: 10.1002/ uog.21909.

29. Zhang L, Han J, Zhang N, et al. Assessment of fetal modified myocardial performance index in early-onset and late-onset fetal growth restriction. Echocardiogra 2019;36(6):1159-1164. DOI: 10.1111/ echo.14364.

30. Villalaín C, Herraiz I, Quezada MS, et al. Prognostic value of the aortic isthmus Doppler assessment on late onset fetal growth restriction. J Perinat Med 2018; 47(2):1-6.

31. Rizzo G, Mappa I, Bitsadze V, et al. Role of Doppler ultrasound at time of diagnosis of late-onset fetal growth restriction in predicting adverse perinatal outcome: prospective cohort study. Ultrasound Obstet Gynecol 2020;55(6):793-798. DOI: 10.1002/uog.20406.

32. Khong TY, Mooney EE, Ariel I, et al. Sampling and definitions of placental lesions Amsterdam placental workshop group consensus statement. Arch Pathol Lab Med 2016;140(7):698-713. DOI: 10.5858/ arpa.2015-0225-CC.

33. O'Callaghan JL, Clifton VL, Prentis P, et al. Modulation of placental gene expression in small-for-gestational-age infants. Genes (Basel) 2020;11(1):80. DOI: 10.3390/genes11010080.

34. Leite DFB, Cecatti JG. New approaches to fetal growth restriction: the time for metabolomics has come. Rev Bras Ginecol e Obstet 2019;41(7):454-462. DOI: 10.1055/s-0039-1692126.

35. Kwiatkowski S, Bednarek-Jędrzejek M, Ksel J, et al. sFlt-1/PIGF and Doppler ultrasound parameters in SGA pregnancies with confirmed neonatal birth weight below 10th percentile. Pregnancy Hypertens 2018;14:79-85. DOI: 10.1016/j.preghy.2018.08.448.

36. Anderson N, De Laat M, Benton S, et al. Placental growth factor as an indicator of fetal growth restriction in late-onset small-for-gestational age pregnancies. Aust New Zeal J Obstet Gynaecol 2019;59(1):89-95. DOI: 10.1111/ajo.12831.

37. Gagnon A, Wilson RD, Audibert F, et al. Obstetrical complications associated with abnormal maternal serum markers analytes. J Obstet Gynaecol Canada [Internet] 2008;30(10):918-932. DOI: 10.1016/S17012163(16)32973-5.

38. Puntachai P, Wanapirak C, Sirichotiyakul S, et al. Associations between pregnancy outcomes and unexplained high and low maternal serum alpha-fetoprotein levels. Arch Gynecol Obstet 2015;292(1):81-85. DOI: 10.1007/s00404-014-3606-9.

39. Morano D, Rossi S, Lapucci C, et al. Cell-Free DNA (cfDNA) fetal fraction in early- and late-onset fetal growth restriction. Mol Diagnosis Ther [Internet] 2018;22(5):613-619. DOI: 10.1007/s40291-018-0353-9.

40. Zou Z, He Z, Cai J, et al. Potential role of microRNA-424 in regulating ERR $y$ to suppress trophoblast proliferation and invasion in fetal growth restriction. Placenta [Internet] 2019;83(July):57-62. DOI: 10.1016/j.placenta.2019.07.001.

41. Colella M, Frérot A, Novais ARB, et al. Neonatal and long-term consequences of fetal growth restriction. Curr Pediatr Rev 2018;14(4):212-218. DOI: 10.2174/1573396314666180712114531.

42. Chen PY, Chu A, Liao WW, et al. Prenatal growth patterns and birthweight are associated with differential DNA methylation and gene expression of cardiometabolic risk genes in human placentas: a discovery-based approach. Reprod Sci 2018;25(4):523-539. DOI: 10.1177/1933719117716779.

43. Monteagudo-Sánchez A, Sánchez-Delgado $M$, Mora JRH, et al. Differences in expression rather than methylation at placenta-specific imprinted loci is associated with intrauterine growth restriction. Clin Epigenetics 2019;11(1):1-15. DOI: 10.1186/s13148-019-0630-4. 